value, mutually forging the links of the chain as it passes from mind to mind and from generation to generation. At the centre of this community is the librarian, with his two main duties of preserving for future readers the books in his care and of caring for the needs of every member of that community and for the chain of recorded tradition which is continually being corrected, strengthened, extended and passed onwards.

Indian Ephemeris and Nautical Almanack (1958)

THE publication of the first issue of the Indian Ephemeris and Nautical Almanack (pp. xviii +392. Delhi: Manager of Publications, 1957. Rs. 12) marks an important step in the plans for the development of astronomical studies in India. The preparation of such a work was first recommended by the Planning Committee for the development of astronomy and astrophysics set up in 1945 under the chairmanship of the late Prof. M. Saha. In 1952, the Government of India appointed a Calendar Reform Committee with the object of unifying the diverse indigenous calendars (see Nature, 178, 402; 1956). This Committee recommended that an Indian Ephemeris and Nautical Almanac for each year should be compiled and issued by the Government. The work was started by the Council of Scientific and Industrial Research under the Ministry of Natural Resources and Scientific Research, but it has now been taken over by the Indian Meteorological Department under the Ministry of Communications, and a Nautical Almanack Section has been set up at the Regional Meteorological Section, Alipore, Calcutta. At the end there is a section on Indian astronomy, added in accordance with the recommendation of the Calendar Reform Committee. The work of compiling and publishing the present issue has been under the supervision of Sri N. C. Lahiri, who has also been responsible for the introduction, dealing with the history and development of astronomy in India from about 1350 B.c.

\section{Vacuum Drying Oven}

The Gardiner precision vacuum oven, developed by S. D. Gardiner in the laboratories of Tate and Lyle for the determination of the loss in weight on heating sugar syrups and molasses, is now in production by Griffin and George, Ltd., Ealing Road, Alperton, Wembley, Middlesex, from whom particulars of it may be obtained. In this oven the sample is taken into solution and distributed over aluminium powder. It is then heated in $a_{\text {o vacuum }}$ while a current of dry air or inert gas is taken over its surface. Suitable arrangements for heating the specimen are incorporated. The oven will be suitable for use with various types of materials, including those of a labile nature.

Developmental Potentialities of Fern Leaf
Frimordia

E. G. CUTTER (Annals of Botany, N.S., 21, 343 ; 1957) has noted that whon young visible primordia, which are not yet determined as leaves, on inactive apices of Dryopteris aristata are isolated by four shallow incisions, they undergo regression and disappear; but if the adaxial incision is afterwards deepened, some of the primordia are stimulated into a renewal of growth. About three-quarters of this number developed as buds, the rest as leaves, some of which were of radial symmetry; others became dorsiventral, but were sometimes abnormally orientated. Such primordia usually underwent a phase of radial symmetry during development. Subsequent deepening of the abaxial or radial shallow incisions was usually without effect. In a discussion of the problems of leaf determination, symmetry and orientation, it is suggested that, in specimens where the isolated primordia developed as leaves, the experimental treatments have merely fortuitously reproduced the regulative effects normally exercised by the shoot apex and adjacent primordia. There may be specific relationships between the size and growth capacity of the primordium and that of the shoot apex on which it is formed. Three phases in the development of a leaf primordium of this species can now be distinguished: inception as a growth centre, determination as a foliar organ of limited growth, and development as an organ of dorsiventral symmetry. Under normal growth conditions, radial leaf development is never observed, but when growth is unusually slow it may become manifest. In other species the temporal relationships between these phases of development may differ, so that they cannot be differentiated by experimental means.

\section{Second International Symposium on Freezing and Drying}

THE Institute of Biology is arranging a symposium on freezing and drying to discuss progress in this field since the first symposium held in 1951. The meeting is to be held in the Beveridge Hall, Senate House, London, W.C.1, on April 1 and 2. Some twenty speakers, including workers from France, Japan, Kenya, the United States and the U.S.S.R., have accepted invitations. The symposium will be open to the public. Further information can be obtained from the Institute of Biology, 41 Queen's Gate, London, S.W.7.

\section{"Structure of Brain Ganglioside"}

WIтH reference to the communication under this title by Dr. Samuel Bogoch published in Nature of July $27(180,197$; 1957), Dr. J. Folch-Pi, director of scientific research, MeLean Hospital (Harvard Medical School), Waverley, Mass,, states that Dr. Bogoch should have mentioned that most of this work was carried out at the McLean Hospital Laboratories, and that it was supported by the American Cancer Society (Grant $B C H-11$ et seq.).

\section{University News :}

London

The British Steel Producers' Conference and the British Constructional Steelwork Association have offered $\mathfrak{£ 6 , 0 0 0}$ a year to the Imperial College of Science and Technology, London, for the establishment of a readership in structural steelwork in the Department of Civil Engineering and the provision of a number of bursaries for postgraduate study in that subject.

Nottingham

THE title of reader in applied mathematics has been conferred on Mr. John Edward Adkins.

\section{The Night Sky in February}

Fuld moon occurs on Feb. 4 d. $08 \mathrm{~h} .05 \mathrm{~m}$ U.T., and new moon on February 18d. 15h. $38 \mathrm{~m}$. The following conjunctions with the Moon take place: Feb. 9d. 14h., Jupiter $2^{\circ}$ N. ; Feb. 13d. 09h., Saturn $2^{\circ}$ S.; 